\title{
VEJA E CARTACAPITAL: OBSERVACOOES INICIAIS DE PESQUISA
}

Vinicius Surigan FERRAZ*

RESUMO

Este artigo visa a tecer as observações iniciais para um futuro projeto de dissertação. Nele, buscou-se observar as ideologias por trás das editorias políticas das duas maiores revistas semanais que representam cada suposto nicho político-ideológico do Brasil: a Veja e a CartaCapital. Utilizando, como arcabouço teórico, a concepção de ideologia proposta por John B. Thompson, juntamente com a metodologia de análise de discurso e seus sustentáculos, poderemos desenvolver um estudo analítico para verificar o discurso e o lugar de fala de ambas as revistas, demonstrando influenciam seu público leitor. O que nos interessa nessas primeiras asserções deste futuro projeto, não é tanto chegar a conclusões de como as revistas funcionam ideologicamente, não é a aplicação dos conceitos estabelecidos aqui, mas sim fazer elucubrações e entender as revistas por meio desses espectros, a fim de criar uma base teórica-metodológica.

Palavras-chave: Ideologia. Análise de Discurso. Veja e CartaCapital.

INTRODUC ÃO

Para José Marques de Melo (2015), o jornalismo constitui uma categoria pertencente à modalidade de comunicação periódica, inserida no conjunto da comunicação massiva, dentro do campo da Comunicação. Ele salienta que se trata de uma categoria comunicacional configurada por classes, aqui

* Jornalista graduado em Comunicação Social - Jornalismo pela PUC-Campinas. Mestrando em Comunicação Social pela Universidade Metodista de São Paulo (UMESP). Bolsista CNPq.

E-mail: vncsferraz@gmail.com 
entendidas como gêneros, que se expressam sob distintas formas, denominadas formatos, replicados, por sua vez em espécies, rotuladas como tipos.

Essa breve explicação acerca desse modelo comunicacional visa a esclarecer que este artigo não tem a intenção de elucidar e de analisar os gêneros e os formatos técnicos do jornalismo, mas sim a influência social e cultural que ele exerce sobre a sociedade, tendo, como pressuposto, ser incapaz de refletir a realidade tal como ela é, na verdade constrói uma representação da realidade, sempre mediada pelos fatores discursivos e ideológicos (BENETTI, 2007b, p. 110-111).

Como se vê, não tentaremos simplesmente aplicar conceitos, métodos e marcos teóricos a um objeto definido de estudo, mas raciocinar em busca das melhores definições teóricas e metodológicas acerca das editorias políticas das revistas Veja e CartaCapital. De fato, ambas constituem nichos político -ideológicos opostos, como atestam inúmeras pesquisas: a primeira dá voz à direita, enquanto a segunda à de esquerda.

A hipótese central deste artigo concentra-se no fato de que a última eleição federal se caracterizou pela polarização política, sempre vivida na sociedade brasileira, mas proporções mais intensas, após o acirramento de ânimos dos eleitores em 2014. Essa radicalização evidenciou a dicotomia ideológico-social entre a direita e a esquerda, a ponto de as editorias deixarem de lado a objetividade jornalística e iniciarem um processo de disputa argumentativa, em prol cada um desses vieses ideológicos.

Utilizaremos, aqui, os conceitos de representação, segundo Stuart Hall (1997), assim como os de ideologia, segundo John B. Thompson, que atualizou o viés marxista. Essa concepção vai além, pois pensa a ideologia como interpretação das formas simbólicas, fato que constitui problema cultural de uma concepção estrutural.

[...]podemos reconhecer que, nas sociedades caracterizadas pelo desenvolvimento da comunicação de massa, a análise da ideologia deve se interessar, fundamentalmente, pelas formas simbólicas transmitidas pelos meios técnicos dessa comunicação. Em vez de concentrar-se nos sistemas de crenças seculares formulados e defendidos por grupos políticos organizados, a análise da ideologia deve orientar-se primariamente, na direção das múltiplas e complexas maneiras como esses fenômenos simbólicos circulam no mundo social e se cruzam com relações de poder. Os meios técnicos da comunicação de massa são de interesse fundamental, não apenas como canais de difusão e circulação das formas simbólicas, mas também como mecanismos que criam novos tipos de ação e interação, novos tipos de relações sociais que se difundem no tempo e no espaço. Por isso, a análise da ideologia deve se preocupar tanto com as 
formas simbólicas que são produzidas e difundidas pelas instituições da mídia, como com os contextos de ação interação dentro dos quais essas formas simbólicas mediadas são produzidas e recebidas. (THOPMSON, B. J. p. 342)

A divisão estrutural simbólica é de grande importância social, já que nos remete a entender melhor como os discursos dominantes circulam através da mídia e como eles impactam seus receptores, mantendo as relações de poder através da transmissão de representações simbólicas por meio da mídia.

JORNALISMO NO BRASIL

A mídia constitui uma das mais importantes fontes de representação política na sociedade. Ela consegue, através do seu poder de difusão, atingir um conjunto muito grande de pessoas. Segundo Roger Silverstone, em seu livro "Por que estudar a mídia?" (Silverstone, 2002, pág. 12), é impossível escapar da presença e da representação da mídia. Baseando-se nessa asserção, iremos demonstrar a cronologia da mídia, mais propriamente um olhar panorâmico sobre o jornalismo no Brasil, a ponto de estabelecer um contexto histórico evolutivo até o nosso objeto de estudo. Isso é peça fundamental para entendermos como a imprensa evoluiu de simples peças espontâneas para uma indústria cultural que atende à lógica mercantil, visando ao lucro.

Segundo Juarez Bahia no livro Jornalismo, Histórica e Técnica no Brasil, a história do jornalismo, em terra tupiniquins, foi dividida em quatro fases. A primeira, de 1808 a (aproximadamente) 1880, compreende o início da imprensa. Essa fase marcou-se pela chegada da Corte portuguesa ao país, quando a Gazeta do Rio de Janeiro, um dos únicos periódicos brasileiros - o outro existente era o Correio Braziliense que, apesar de pioneiro, era impresso em Londres e chegava ilegalmente ao Brasil -, se restringia a publicações de decretos da Corte sobre a rotina da família Real, além de focar quase restritivamente, o que acontecia na Europa. Tal etapa ficou marcada pela censura editorial, ocasionando entraves ao seu desenvolvimento (SODRÉ, Nelson Werneck). Com o pioneirismo do Correio Braziliense, começaram a pipocar alguns outros jornais brasileiros, mas faltavam condições políticas para que maiores e melhores periódicos florescessem. Eles surgiram anos depois, a partir do desejo de independência de Portugal, fator que multiplicou os órgãos impressos que defendiam a abdicação de D. Pedro I, corrida em 7 de abril de 1831. Os pasquins, panfletos de cunho político, com linguagem desabrida e sem comprometimento com a veracidade e a apuração dos fatos também se destacaram no período. 
[...] na verdade, o período de 1830 a 1850 foi o grande momento da imprensa brasileira. Fraca em técnica, artesanal na produção, com distribuição restrita e emprestada, praticamente inexistente uma vez que inespecífica, encontrou, entretanto, na realidade política a fonte de que se valeu para exercer sobre essa realidade, por sua vez, influência extraordinária, consideradas as condições da época. Foi, praticamente, a infância da imprensa brasileira; talvez a sua turbulenta adolescência, quando muito, se considerarmos infância a curta fase em que batalhou pela liberdade conjugada à independência do país. ${ }^{1}$ (SODRÉ, Nelson Werneck apud HOHLFELDT, A. C.; VALLES, Rafael R., p.71)

Possuindo já uma figura administrativa e um apelo empresarial distinto dos demais, surgiu, em 1875, o jornal A Província de São Paulo, mais tarde, $O$ Estado de S. Paulo. A história dele dá início à segunda fase do jornalismo no país o qual passa a viver a passagem do Brasil imperial escravista para uma república industrializada e pluralista.

Marcada pela consolidação da imprensa no país, a segunda fase, como sugerida por Bahia, de 1880 até 1930. Segundo Bahia, ela constituía da aventura industrial, e, sobretudo, da consolidação, já que o jornal começa a tomar a forma de empreendimento mercantil.

Não só o processo de feitura, com a introdução da nova maquinaria e a equação do jornal como empresa gráfica autônoma, independente da tipografia, que tomou o caráter comercial, para servir às chamadas casas de obras, mas igualmente a qualificação do jornalismo como profissão, a necessidade de expansão e criação de mercados consumidores internos e externos, o advento da propaganda como fonte de renda e organização específica, as responsabilidades estimadas na legislação própria, são aspectos de primeira plana no desenvolvimento da imprensa, na sua segunda fase, a fase da aventura industrial e de consolidação. (BAHIA, Juarez apud HOHLFELDT, A. C.; VALLES, Rafael R., p.71)

Alavancado pela ascensão do café em âmbito nacional e, consequentemente, pelo crescimento econômico, pela urbanização da sociedade e pela ampliação do mercado, a imprensa, consolidou-se no país como empresa, preocupando-se com a distribuição do produto jornalístico, com a exigência do público, com a periodicidade, com a informação e com os recursos técnicos diferenciados. O Jornal do Brasil, O Globo, a Folha de São Paulo, a Gazeta Mercantil e a revista O Cruzeiro constituem bons exemplos desse processo.

Citação de Nelson Weneck Sodré no livro Conceito e História do Jornalismo Brasileiro na "Revista de Comunicação" de Antonio Hohlfeldt e Rafael Rosinato Valles 
Para Juarez Bahia, a partir dessa lógica, os principais jornais para adquiriram expressão, além de e capitais material, econômico e intelectual.

A terceira fase do jornalismo brasileiro é marcada pela evolução sociopolítica nacional, já que ocorreu em meio à revolução de 1930, ao fim da República Velha, ao início do Estado Novo, em 1937 (com a implementação da censura) e à volta da liberdade de imprensa, em 1945, e ao golpe militar, no ano de 1964.

É marcada, ainda, pela transição entre a decadência do jornalismo opinativo, característica principal da primeira fase da imprensa brasileira, e a ascensão do jornalismo informativo. Isso significa uma libertação do modelo europeu jornalístico, já que se o estilo norte-americano, noticioso e seco. ${ }^{2}$ A característica denunciativa sobre os atrasos socioeconômicos do país constituiu uma das questões primordiais para que a tensão que caía sobre a liberdade de imprensa subisse à tona. Nesse contexto, os periódicos formados durante a segunda fase se consolidaram e compuseram o mercado da imprensa durante as décadas de 1930 e 1940. (HOHLFELDT, A. C.; VALLES, Rafael R. Pág. 74).

Esta fase moderna traria ainda, para a imprensa, outras alterações profundas. A influência norte-americana se consolida no jornalismo nacional, ao longo da década de 1950, firmando, assim, o jornalismo informativo. Um dos mais significativos exemplos das transformações da linguagem jornalística, ocorridos sob a influência norte-americana, é o surgimento do lead na imprensa nacional, através da iniciativa de Pompeu de Souza, Danton Jobim e Luís Paulistano, efetivada no Diário Carioca, em meados dos anos 1950 [...] O lead tem como característica ocupar o primeiro parágrafo da notícia com o resumo conciso das informações mais novas e principais do texto, buscando esclarecer as seguintes questões relativas ao fato: Quem? O quê? Onde? Quando? Como? Por quê?

A terceira fase não se limita apenas à atuação da imprensa, já que o rádio foi implantado no Brasil, nem meados dos anos 1920. Após bastante utilizado na Primeira Guerra e depois de alguns anos em experimentação nos Estados Unidos, o veículo chegou a todas as classes sociais, sem distinção, papel que não cabia ao jornalismo impresso, destinado somente aos letrados. A hegemonia da Rádio Nacional, no Rio de Janeiro, e da Rádio Record, em São Paulo, marcam os anos 1930. Assis Chateaubriand teve participação muito importante nesse período da comunicação e do jornalismo no Brasil ao tornar-se o primeiro proprietário de um conglomerado de comunicação,

RIBEIRO, Jorge Cláudio. 
somando, ao todo, 31 jornais, quatro revistas, 26 emissoras (cinco de televisão) e uma agência noticiosa: Diários e Emissoras Associados. ${ }^{3}$

Como poucos, Chateaubriand soube aproveitar a reabertura política de 1945 e a consequente liberdade de imprensa para impor o seu poderio capitalista e consolidar um aspecto que caracteriza até hoje as empresas jornalísticas nacionais: o poder de concentração

A empresa jornalística, mesmo tomada isoladamente, tem já dimensões e complexidades tais que o capital para montá-la está ao alcance de poucos. No Brasil, por isso, desapareceu a pequena imprensa; só a grande existe. (...) não seria fácil, hoje, fazer um novo jornal: as relações capitalistas, nesse campo, estão acabadas, amplas, imperiosas, dominadoras, as empresas existentes, por sua vez, ampliam-se, incorporam revistas, emissoras de rádio e de televisão. ${ }^{4}$

Nesse contexto incluem-se outros grandes complexos jornalísticos, como a Editora Abril. Criada em julho de 1950, a empresa possui um império editorial de 102 títulos, com uma circulação anual de mais de 120 milhões de exemplares. Proprietárias da antiga revista Manchete e Empresas Bloch, também constituem um exemplo de conglomerados de mídia, já que possuíam uma cadeia de empresas que englobava a Rádio Manchete e a Rede Manchete de Televisão. No final dessa fase, formou-se, a partir de um acordo firmado entre a empresa norte-americana Time Life e o grupo de comunicação de Roberto Marinho, a TV Globo. Marinho, proprietário do jornal O Globo e de outras emissoras de rádio, transformou, nas décadas seguintes, a empresas tornando-a o maior conglomerado comunicacional do país.

O início da quarta e última fase do jornalismo brasileiro marcou, para a imprensa, de um modo geral, um movimento jornalístico de cunho sociopolítico, já que existia a censura estabelecida pela Ditadura Militar. Nessa fase, instauraram-se jornais alternativos para contestar, por meio de ativismo político, o regime vigente.

A imprensa alternativa surgiu da articulação de duas forças igualmente compulsivas: o desejo das esquerdas de protagonizar as transformações que propunham e a busca, por jornalistas e intelectuais, de espaços alternativos à grande imprensa e à universidade. É na dupla oposição ao sistema representado pelo regime militar e às limitações à produção intelectual-jornalística sob o autori- 
tarismo que se encontra o nexo dessa articulação entre jornalistas, intelectuais e ativistas políticos. ${ }^{5}$

Tais jornais não duravam muito, já que viviam no alvo da repressão censória da ditadura. Esse tipo de imprensa começou a desaparecer a partir da abertura política da década de 1980, pois perdeu espaço ou foi agregada aos sindicatos e aos partidos políticos. A greve da região do ABC, que originou o Partido dos Trabalhadores (PT), exemplifica essa tese.

Ciro Marcondes Filho vê, nesta fase, o jornalismo da era tecnológica, onde se acoplam dois processos: a expansão da indústria da consciência, no plano das estratégias de comunicação e persuasão, dentro do noticiário e da informação; e a substituição do agente humano jornalista pelos sistemas de comunicação eletrônica, pelas redes, pelas formas interativas de criação, fornecimento e difusão de informações. ${ }^{6}$

\section{REPRESENTAÇOEES IDEOLÓGICAS}

Contextualizado o panorama evolutivo da imprensa no Brasil, partimos para os conceitos de representação ideológica, propostos por Stuart Hall (1997) no livro "O trabalho da representação" (The work of representation). Ele afirma que o senso comum somente se cria após a partilha de significados. Esse é o cerne de como ele explica a representação: um jogo de significados, culturalmente interpretados pela sociedade. No caso deste artigo, as duas revistas focalizadas, através de suas editorias políticas, hipoteticamente, trabalham com esse mesmo elemento: a criação de consenso entre seus eleitores, a partir de determinada ideologia.

O referencial teórico para explicar o significado de ideologia é o conceito escrito por John B. Thompson (2011) no livro Ideologia e Cultura: teoria social crítica na era dos meios de comunicação de massa. O autor se baseia entre o conceito pessimista frankfurtiano, que pensava a ideologia como cimento social, definição amplamente apropriada pelos meios de comunicação de massa para disseminar formas simbólicas ou usado como mecanismo social moderno para difundir as ideias do grupo dominante, com a finalidade de dominação.

Horkheimer e Adorno argumentaram que o surgimento das indústrias de entretenimento como empresas capitalistas resultou na padronização e na

KUCINSKI, Bernardo. Jornalistas e revolucionários: Nos tempos da imprensa alternativa. São Paulo, EDUSP, 2003, p. 16.

6 HOHLFELDT, A. C.; VALLES, Rafael R. Ibidem. Pág. 79 
racionalização das formas culturais, e esse processo, por sua vez, atrofiou a capacidade do indivíduo de pensar e agir de uma maneira crítica e autônoma (... ) A análise da indústria cultural feita por Horkheimer e Adorno representa uma das tentativas mais corajosas realizadas por teóricos sociais e políticos para compreender a natureza e as consequências da comunicação de massa nas sociedades modernas. (THOMPSON, J. B. p.134)

Segundo o autor, o pensamento economicista sobre a comunicação de massa é limitado, porque não possui a capacidade de abarcar a multiplicidade de sentidos da qual o conceito necessita. Ou seja, não se mostra totalmente evidente que, ao receber e consumir os produtos da indústria cultural, os indivíduos sejam levados a aderir à ordem social, a identificar-se com as imagens projetadas e a aceitar, sem senso crítico, a sabedoria proverbial veiculada (THOMPSON J. B. p. 138). Pinto também faz essa crítica ao marxismo ao elucidar a questão ideológica, que, segundo ele, também não deve ser o único fator essencial nessa análise de discurso. Existem outros fenômenos socioculturais, como as diferenças sociais, como as de sexo, idade, raça ou religião.

Não é mais aceitável pensar uma relação casual rígida, invariável, mecânica e exclusiva entre "infraestrutura", onde só os fatores econômicos contrariam, e a "superestrutura", domínio único do ideológico, do discurso. O número de variáveis em jogo em qualquer fenômeno social, e em especial nos fenômenos de comunicação, não só é grande, como seu relacionamento bastante complexo e indecidível, e fica difícil falar em determinação em última instância por este ou aquele fator, qualquer que seja. (PINTO, Milton José, p. 48).

Assim como Thompson e Pinto, Douglas Kellner argumenta que o conceito de ideologia precisa de atualização e de novos enfoques para considerar que os instrumentos de dominação, expressos pela sua ação, podem representar também, a opressão do sexo, da sexualidade e da raça - além dos fatores ligados à economia e à classe social (KELLNER, 2001, p. 79). Thompson também não chega a usar o conceito fraco, proposto pela dicotomia entre fraco e forte, de Bobbio (2000), que contempla uma visão amiúde reducionista da ideologia como uma "crença falsa". A concepção de Thompson sobre estudar a ideologia equivale a estudar as maneiras como o sentido serve para sustentar relações de dominação (p. 76). Ou seja, interessa-se, primeiramente, em identificar como as formas simbólicas se entrecruzam com relações de poder. 
Fenômenos ideológicos são fenômenos simbólicos significativos desde que eles sirvam, em circunstâncias sócio-históricas específicas, para estabelecer e sustentar as relações de dominação. Desde que: é crucial acentuar que fenômenos simbólicos, ou certos fenômenos simbólicos, não são ideológicos como tais, mas são ideológicos somente enquanto servem, em circunstâncias particulares, para manter relações de dominação. Não podemos derivar o caráter ideológico dos fenômenos simbólicos dos próprios fenômenos simbólicos. Podemos compreender os fenômenos simbólicos como ideo1ógicos e, por isso, podemos analisar a ideologia somente quando situamos os fenômenos simbólicos nos contextos sócio-históricos, dentro dos quais esses fenômenos podem, ou não, estabelecer e sustentar relações de dominação. (THOMPSON, J. B. p. 76)

Tal definição aplica-se ao caso de nossa pesquisa pois, utilizamos as revistas como fenômenos simbólicos, que, e servem ou não - um caso analítico - para estabelecer relações de dominação. Isso será possível somente ao examinar como essas formas simbólicas são empregadas, transmitidas e compreendidas por pessoas situadas em contextos sociais estruturados. (THOMPSON, J. B.)

(...) estas formas simbólicas estão também inseridas em contextos e processos sócio-históricos específicos dentro dos quais, e por meio dos quais, são produzidas, transmitidas e recebidas: Estes contextos e processos estão estruturados de várias maneiras. Podem estar caracterizados, por exemplo, por relações assimétricas de poder, por acesso diferenciado a recursos e oportunidades e por mecanismos institucionalizados de produção, transmissão e recepção de formas simbólicas. A análise dos fenômenos culturais implica a elucidação destes contextos e de processos socialmente estruturados, bem como a interpretação das formas simbólicas. (THOMPSON J. B. p.181).

Nesse caso, é permitido dizer que os Estudos Culturais Ingleses nortearam Thompson, já que definem cultura como a forma pela qual a sociedade consegue interpretar as representações simbólicas através da indústria cultural - nela inseridas as comunicações de massa - e como essas interpretações conseguem fomentar pré-conceitos, ou ideias de realidade, a ponto dessas representações sustentarem uma ideologia por trás disso.

O grupo do CCCS amplia o conceito de cultura para que sejam incluídos dois temas adicionais. Primeiro: a cultura não é uma entidade monolítica ou homogênea, mas, ao contrário, manifesta-se de maneira diferenciada em qualquer formação social ou época histórica. Segundo: a cultura não significa simples- 
mente sabedoria recebida ou experiência passiva, mas um grande número de intervenções ativas - expressas mais notavelmente através do discurso e da representação - que podem tanto mudar a história quanto transmitir o passado. Por acentuar a natureza diferenciada da cultura, a perspectiva dos estudos culturais britânicos pode relacionar a produção, distribuição e recepção culturais a práticas econômicas que estão, por sua vez, intimamente relacionadas à constituição do sentido cultural. (AGGER, Ben, p.89)

Os fundadores dos Estudos Culturais - Raymmond Williams, Edward Palmer Thompson e Richar Hoggart - seguem a mesma linha teórica de Thompson, pois pressupõem que, através das formas textuais e das práticas documentadas de cultura, seja possível reconstituir o comportamento padronizado e as constelações de ideias por quem produz e consome os textos e as práticas culturais daquela sociedade. Tal perspectiva enfatiza a atividade humana e a produção ativa da cultura, ao invés de seu consumo passivo (STOREY, John, p.1997), estimulando certa autonomia do indivíduo quanto à indústria cultural.

\section{VEJA E CARTACAPITAL E A DIREITA E ESQUERDA NO DEBATE POLÍTICO BRASILEIRO}

Após traçarmos o panorama transformacional da imprensa desde o seu nascimento e entendermos a teoria que nos embasa a análise, faz-se necessário apresentar algumas referências relativas as duas revistas às duas revistas que constituem o corpus de nossa pesquisa: Veja e CartaCapital.

Produzida pela editora Abril, a Veja, considerada por muitos uma espécie de escudo neoliberal no Brasil, utiliza uma linguagem mais dura ao abordar a economia e a política. A empresa, cuja linha editorial foi contrária às gestões petistas (2002 a 2016), agrupa profissionais com opiniões mais conservadoras. O periódico busca, através de suas reportagens defender o livre mercado, a individualidade, a não intervenção do Estado (Estado Mínimo) e o conservadorismo cultural e religioso.

É esse o sentido do peso que é dado pela revista para a cobertura dos fatos políticos. Através deles, abrem-se ou fecham-se espaços para os diferentes interesses industriais, comerciais, bancários ou financeiros. A cobertura política se dá não porque a revista esteja interessada em pormenores do Congresso Nacional ou do Poder Executivo, mas porque nesses embates estão em jogo decisões fundamentais como: "livrar-se do fardo" da Constituição de 1988; impedir qualquer controle capital, sobretudo externo; privatizar; retirar funções sociais do Estado. A revista agiu muitas vezes nesses debates da grande política 
como partido, organizando e encaminhando a hegemonia dos grupos que defende e o consenso em torno de seu projeto. (SILVA, Carla, 2005, p.23)

Já a revista CartaCapital, fundada em 1994, é produzida pela editora Confiança. O periódico busca interagir com a ideologia de centro-esquerda e utiliza em seus discursos, argumentos a favor de um maior controle estatal econômico, da interferência do governo em quase todos os setores sociais e da igualdade como um dos pilares ideológicos, acima de outros fatores de ordem cultural, moral e religiosa.

Traz em seu corpo editorial, colunas e parcerias, reconhecidas personagens de parte da esquerda, além de abordar temas políticos, econômicos e culturais mais progressistas. Caracterizou-se por apoiar os governos petistas, antes e após a vitória de Lula em 2002. (FERNANDES, Pedro V; 2016, p.43).

Vale ressaltar que os conceitos entre direita e esquerda são abrangentes e, por essa razão, faz-se necessário oferecer algum suporte teórico para entendê-los. Os conceitos e as terminologias sobre a 'direita' e a 'esquerda' têm suas raízes na Revolução Francesa, no final do século XVIII. (1789). Era a forma como sentavam os membros da Assembleia Nacional, da Assembleia Legislativa e da Convenção Nacional.

Segundo Gustavo Jorge Silva, as nomenclaturas direita e esquerda são endossadas no Brasil, mas em outros países, são denominadas conservadores e liberais, Silva traça um panorama conceitual sobre a evolução teórica que certos pensadores definiram sobre os termos:

Hayek (1999), em uma tentativa de sintetizar as classificações de liberais $\times$ socialistas e de conservadores $\times$ liberais, propõe que não haja um eixo, mas um triângulo no qual ele situa os liberais em uma das pontas, os conservadores na outra e os socialistas na restante, combinando posições econômicas e valores no mesmo diagrama. Giddens (1996) também faz um esforço sintetizante, de modo a demonstrar a emergência de uma terceira via que articula atributos da esquerda e da direita. Bobbio (2001) posiciona-se no sentido de que a tensão entre esquerda e direita permanece viva e que o fundamento da diferença entre as concepções é a noção que cada uma das tendências tem de igualdade e de desigualdade. A posição dos autores europeus não será profundamente analisada neste trabalho, que passa a tratar agora da construção desse debate no Brasil. (SILVA, Gustavo Jorge, p. 151) 
Ainda de acordo com o autor, essas linhas ideológicas, no Brasil, consistem em conhecimentos intuitivos, ou seja, tal filiação ideológica não tem um significado próprio, constitui mais um sentimento subjetivo.

Nesse caso, utilizaremos a concepção de direita e esquerda definida por Silva, a partir da teoria de Norberto Bobbio, que contempla a noção de que cada ideologia tem relação a igualdade e de desigualdade.

\section{A ANÁLISE DE DISCURSO: UMA REFLEXÃO TEÓRICO-METODOLÓGICA}

A partir daqui, daremos ênfase ao melhor entendimento sobre o método e as teorias relacionadas à análise de discurso e às práticas investigativas, para propor reflexões teórico-metodológicas a fim de evidenciar e revelar o discurso ideológico das editorias políticas de Veja e CartaCapital.

Para isso, acreditamos que, após o aprofundamento nos objetos de estudo, a melhor maneira de desvendar as ideologias é a análise qualitativa dos sentidos explicitados. A escolha da análise de discurso foi feita pois, ao apresentar as definições sobre ideologia, propostas por Thompson (2009), não teríamos, nos textos das duas revistas, suficientes palavras determinantes para que pudéssemos quantificar essa definição. Como o este estudo pretende analisar, ideologicamente, dois veículos de comunicação, esse tipo de interpretação está intimamente ligado com o estudo discursivo e, consequentemente, com o entendimento do enunciado e seu contexto, como define Dmonique Maingueneau:

Compreender um enunciado não é somente referir-se a uma gramática e um dicionário, é mobilizar saberes muito diversos, fazer hipóteses, raciocinar, construindo um contexto que não é um dado preestabelecido e estável. A própria ideia de um enunciado que possua um sentido fixo fora de contexto torna-se insustentável. Certamente isso não quer dizer que as sequências lexicais de uma unidade verbal não signifiquem nada nem que suas relações deixem de orientar decisivamente a interpretação. O que se quer dizer é que, fora de contexto, não podemos falar realmente do sentido de um enunciado. (MAINGUENEAU, Dominique p. 20)

É preciso entender que, na reflexão contemporânea sobre a linguagem, o contexto é imprescindível para a interpretação dos sentidos num enunciado. Pela teoria do discurso, podemos dizer que todas as ações e objetos são significados de acordo com um sistema de regras, inserido num dado momento histórico. Para tanto, segue um exemplo: moradores de uma área em que precisa ser construída uma estrada. Aos que constroem, os residentes 
representam um empecilho ao desenvolvimento da obra, mas, na perspectiva dos habitantes, significa perder as suas casas, como afirma Pinto:

Para a análise de discursos, cada texto pertence a um gênero de discursos ou a uma espécie de discursos e, para cada gênero ou espécie, cabe determinar o que se chama dispositivo de enunciação: a explicitação dos diferentes posicionamentos ideológicos ou posições enunciativas ou ainda lugares de fala - ou seja, as diferentes maneiras de construir a representação de uma determinada prática social ou área de conhecimento propostas pelos sujeitos que aparecem nos textos e que são assumidos ou não pelos participantes do evento comunicativo em curso. (PINTO, Milton José, ANO, pág. 32).

Os discursos embutidos nos textos das revistas funcionam, basicamente, dessa maneira, já que representam perspectivas ideológicas intrínsecas nas editorias políticas em Veja e CartaCapital, e que, através de seus enunciados - lugares de fala -, denotam os posicionamentos ideológicos direita e de esquerda, respectivamente. Isso se vale de pesquisa, pois parece fato que existem efeitos ideológicos por trás dos enunciados contidos nas revistas e, a obviedade que isso não é problemático também é um efeito ideológico. (PINTO, Milton J. p.31).

Desse modo, faz-se necessário diferenciar enunciado de enunciação. Para Maingueneau, o enunciado pode ser puramente definido como uma "sequência verbal (2002, p. 21). Já a enunciação constitui o ato de produção de um texto e se opõe a enunciado, que é o produto cultural, materialmente considerado (PINTO, 2002, p. 32). Por tanto, o enfoque do atual estudo não recai nas condições de produção das reportagens nas revistas, mas, sim investigar os sentidos ideológicos representados nos discursos midiáticos em ambas as revistas. Não temos a intenção aqui de negar a possibilidade de que os receptores possam não aderir ao sentido ideológico do enunciador, porém, não dá para se negar que exista essa pretensão nos textos e isso se vale do contexto e da situação dos assuntos abordado. Fica claro que os enunciados das revistas carregam sentidos e, assim, como produtos culturais - revistas brasileiras designadas à sociedade brasileira - delimitam a incidência sobre determinado público. Nesse sentido, o estudo do enunciado das revistas, onde também se delimitam os contextos históricos, auxilia esta pesquisa. Travemse essas disputas consensuais por meio dos textos. De acordo com Pinto:

Definir os discursos como práticas sociais implica que a linguagem verbal e as outras semióticas com que se constroem os textos sejam partes integrantes do contexto sócio-histórico e não alguma coisa de caráter puramente instrumen- 
tal, externa às pressões sociais. Têm assim papel fundamental na reprodução, manutenção ou transformação das representações que as pessoas fazem e das relações e identidades com que se definem na sociedade, pois é por meio dos textos que travam as batalhas que, no nosso dia-a-dia, levam os participantes de um processo comunicacional a procurar dar a última palavra, isto é, a ter reconhecido pelos seus receptores o aspecto hegemônico do seu discurso. (PINTO, Milton José, ANO, pág. 28).

\section{CONCLUSÕES}

Ao fazer toda essa trajetória histórica, teórica e metodológica, conseguimos, através deste artigo, propor um espectro de pesquisa, explanar alguns conceitos referente ao objeto de estudo e elucidar questões de cunho epistêmico.

Portanto considera-se que a tarefa proposta foi criar um alicerce teórico e metodológico para analisar as editorias políticas das revistas Veja e CartaCapital visando, no futuro, aplicar esses conceitos à elucidação das ideologias por trás das representações simbólicas que ambas reproduzem a seus públicos, tentando detectar alguns aspectos dessa polaridade política, vigente na sociedade brasileira.

\section{REFERÊNCIAS}

SANTI, H. C.; SANTI, U. J. C. Stuart Hall e o Trabalho das Representações. Revista Anagrama Revista Interdisciplinar da Graduação do grupo de estudos de linguagem da ECA/USP, ano 2, edição 1, setembro/novembro de 2008. Disponível em: http://www.revistas.univerciencia.org/index.php/anagrama/ article/viewFile/6288/5712.

ASSIS, Francisco de; MARQUES DE MELO, José. Gêneros e formatos jornalísticos: um modelo classificatório. Intercom - RBCC. São Paulo, v.39, n.1, p.39-56, jan./abr. 2016. Disponível em: http:// www.scielo.br/pdf/interc/v39n1/1809-5844-interc-39-1-0039.pdf

BAHIA, Juarez. Jornal, história e técnica. São Paulo: Ática, 1990

BENETTI, M.; LAGO, C. Análise do discurso em jornalismo: estudo de vozes e sentidos. Metodologia de pesquisa em jornalismo. Petrópolis, RJ: Vozes, 2007b, p. 107-122. - (Coleção Fazer Jornalismo). ISBN 9788532635037.

ESCOSTEGUY, Ana Carolina D. Estudos culturais. Revista FAMECOS, Porto Alegre. Disponível em: http://www.pucrs.br/famecos/pos/cartografias/Cartografias/artigos/estudos culturais ana.pdf

HOHLFELDT, A. C.; VALLES, Rafael R. Conceito e história do jornalismo brasileiro na Revista Comunicação. Revista FAMECOS, Porto Alegre: PUCRS. Disponível em: http://www.pucrs.br/edipucrs/conceitoehistoria.pdf

KELLNER, D. A cultura da mídia - estudos culturais: identidade e política entre o moderno e o pós-moderno. Tradução de Ivone Castilho Benedetti. 1. ed. São Paulo: EDUSC, 2001. 454 p., 23 cm. (Verbum).

KUCINSKI, Bernardo. Jornalistas e revolucionários: Nos tempos da imprensa alternativa. São Paulo, EDUSP, 2003, p. 16. 
MAINGUEnEAU, D. Análise de textos de comunicação. Tradução de Cecília P. de Souza-e-Silva, Décio Rocha. 2. ed. São Paulo: Cortez, 2002. 238 p., 22 cm. ISBN 8524907789.

SILVA, Gustavo Jorge. Conceituações Teóricas: Esquerda e Direita. Humanidades em Diálogo (Impresso), v. VI, p. 149-162, 2014.

SINGER, André. Esquerda e Direita no eleitorado brasileiro. São Paulo: Edusp, 2000.

THOMPSON, J. B. Ideologia e cultura moderna: teoria social crítica na era dos meios de comunicação de massa. 8. ed. Petrópolis, RJ: Vozes, 2009. 431 p. ISBN 978832614841. 